\title{
Assessment of Chlorophyll-A, SST and Diffuse Attenuation Coefficient (Kd490) in Northwest of Persian Gulf using Landsat 8 Satellite Data
}

\author{
Ahmad Savari1', Laleh Mosavi Dehmordi1 ${ }^{1}$, A Dostshenas ${ }^{1}, \mathrm{H}$ \\ Mohamad Asgari', Alireza Abasi ${ }^{2}$
}

\author{
${ }^{1}$ Khorramshahr University of Marine Science and Technology \\ ${ }^{2}$ Army Geographic Agency
}

\begin{abstract}
The objective of this research was to develop a model for estimating chlorophyll-a, SST and kd(490) on the Northwest Persian gulf water using relatively high resolution landsat 8 image. A field compaign were conducted in Feb, March, April, May, July, Agust, Oct and Nov of 2014 concurrent to satellite over-pass. The field work were conducted of Mahshar estuary between Feb, $14^{\text {th }}$ to Nov, $13^{\text {th }}, 2014$. Temperature, Secchi disk depth, chl-a, kd and zeu was measured in this study. We tested various regression models using combinations of bands. The regression models showed acceptable correlation and accuracy. The Chl-a concentrations ranged from 0.6 to $1.8 \mathrm{mg} \mathrm{m}-3$, with an average of $1.01 \pm 0.32 \mathrm{mg} \mathrm{m}^{-3}$. The values for $\mathrm{Kd}(490)$ were highest $(0.86)$ in July and lowest $(0.59 \mathrm{~m})$ in February. Deeper Zeu are observed in Feb $(7.8 \mathrm{~m})$ and Shallower Zeu were observed in July $(5.3 \mathrm{~m})$. The study of SST algorithm model for Landsat-8 data has been conducted using the method approached to SST derived from calibrated landsat8 data. The retrieval accuracy $\left(\mathrm{R}^{2}\right)$ was 0.63 , while the root mean square (RMSE) was 0.81. The highest $\left(31 \mathrm{c}^{\circ}\right)$ temperature was found in July and lowest temperature $\left(15.1 \mathrm{c}^{\circ}\right)$ was found in Feb. The approach employed in this research indicates that remote sensing is a valuable, low-cost and stable tool for water quality monitoring of estuary health.
\end{abstract}

Keywords: Landsat8, Chl-a, SST, kd(490), zeu

\begin{abstract}
Introduction
Coastal and estuarine primary productivity, as indicated by chlorophyll concentrations, is an important part of any estuarine or coastal ecosystem that is often influenced by freshwater inflow, nutrient loading, salinity and other environmental conditions (Arismendez et al., 2009 ). Numerous bio-optical algorithms have been developed to estimate chlorophyll a (C) or chlorophyll a concentration from ocean radiance data. Most of these are empirical relations derived by statistical regression of radiance versus chlorophyll. In-situ measurements combined with satellite data on the same day has affected the development and evaluation of accuracy and precision of ocean color chlorophyll algorithms.
\end{abstract}

A common index of water quality is water clarity, estimated by the diffuse attenuation coefficient for downwelling irradiance $(\mathrm{Kd})$. This parameter allows prediction at various depths of the availability of light to marine organisms including coral and seagrass communities (Duarte, 1991). Programs to monitor and understand water quality and ecologic health in coastal ocean areas are conducted around the world. Most, if not all, programs lack the high frequency and synoptic scope required to understand the high spatial and temporal variability that is typical of coastal environments.

\footnotetext{
Thermal infrared (TIR) remote sensing technique is a useful approach to monitor the change of water temperature (Schott 1982; Schott et al. 2001; Ritchie and Cooper 2001). The difficulty of atmospheric correction limits the use of OLI, TIR bands in coastal and inland waters (Ritchie and Cooper 2001; Schott et al., 2001). To overcome
}

This article is published under the terms of the Creative Commons Attribution License 4.0

Author(s) retain the copyright of this article. Publication rights with Alkhaer Publications.

Published at: http://www.ijsciences.com/pub/issue/2016-05/

DOI: 10.18483/ijSci.953; Online ISSN: 2305-3925; Print ISSN: 2410-4477 
this limit, many researchers (Chen et al., 2003; Suga et al., 2003; Thomas et al., 2002) have developed local empirical algorithms to retrieve SST on the basis of the radiance or DN value of Ladnsat-8 OLI, TIR data, and no atmospheric correction work needs to be done. However, these empirical algorithms based on Landsat-8 OLI are exclusive, and can not be applicable to each other, which makes it difficult to use the two different sources of data.

Estuarine environments are amongst the most productive and sensitive ecosystems. Their importance in terms of carbon fixation, fisheries habitat, nutrient assimilation, water storage and sediment stabilization has been recognized for a long time (Baban, 1997). However, only a small amount of information is available on their spatial and temporal variability. This might be due to the fact that estuaries are dynamic systems which undergo numerous daily changes. In reality, the large size of estuaries and their spatial and temporal variability limits the effectiveness of sampling stations and interpolation techniques, and, consequently, the perceived picture deviates considerably from reality. On the other hand the physiology of organisms within estuarine habitats depends on suspended solids, turbidity, temperature, salinity, chlorophyll a and total phosphorus concentrations. Therefore, there is a need for information concerning these environmental indicators, in particular for information on their spatial and temporal variability within the estuary.

Landsat-8 Orbital Land Imager (OLI) provide a well-calibrated continuous record $30 \mathrm{~m}$ multispectral data While remote sensing platforms, such as the Advanced Land Imager (ALI), Hyperion, or Moderate Resolution Imaging Spectroradiometer (MODIS) sensors, provide higher radiometric or spectral resolution, the data produced is unsuitable to monitoring purposes. OLI provide both high temporal and spatial resolution, a combination not found in these other data products(Lee et al., 2005).

In this study we sought to determine the appropriate algorithms to apply to satellite observations for the estimation of water clarity and
SST and chla in estuaries waters Khozestan province and the west northern Persian gulf.

\section{Data and methods \\ Water quality sampling and measurements}

Field studies were conducted in Feb, March, April, May, July, Agust, Oct and Nov, from water concurrent with the passage of satellite in Mahshahr estuaies on 14th Feb 2014 to 13th Nov 2014 from 3 stations. Located in the Khozestan province, northwest Persian gulf, is an important water resource for Mahshahr City and Iran County. Water temperature were measured with a thermometer. For each water sample, transparency (Secchi disk depth, SDD) was measured with a Secchi disk at the shade side of the boat. The spectral upwelling radiance at depth $\mathrm{z} \operatorname{Lu}(\lambda, \mathrm{z})$ and $\operatorname{Ed}(\lambda, z)$ (the spectral downwelling irradiance at depth z) were measured with a MER2040 spectroradiometer (Biospherical Instruments, Inc). A surface water sample was collected with a polyethylene bottle for chla laboratory analysis. Sample position were recorded by a portable Global Positioning System (GPS). Figure 1 displays the 3 statioin as representatives to show the sample distribution pattern(Figure 1). After sampling, water samples were conserved in bottles at a low temperature and then sent for laboratory analysis in the afternoon. Samples for chlorophyll a were filtered on $\mathrm{GF} / \mathrm{F}$ fiberglass filters $(25 \mathrm{~mm}$ diameter). The Chl-a was extracted using acetone $(100 \%)$ and was measured using reverse-phase high-performance liquid chromatography (HPLC). The HPLC method employed was that proposed by Wright et al., (1991) slightly modified as per Hooker et al. (2000).

\section{Landsat8 images}

Eight cloud free images of path 165 and row 39 from Feb to Nov 2014 have been downloaded from Glovis (http://glovis.usgs.gov/). The geometric and radiometric correction of the Landsat-8 OLI image was done as preprocessing. Atmospheric correction was conducted using method of dark object subtraction technique (DOS)(Kim et al., 2014). It is an image-based model that has been proposed to simplify atmospheric correction. The image were processed in Matlab software. 


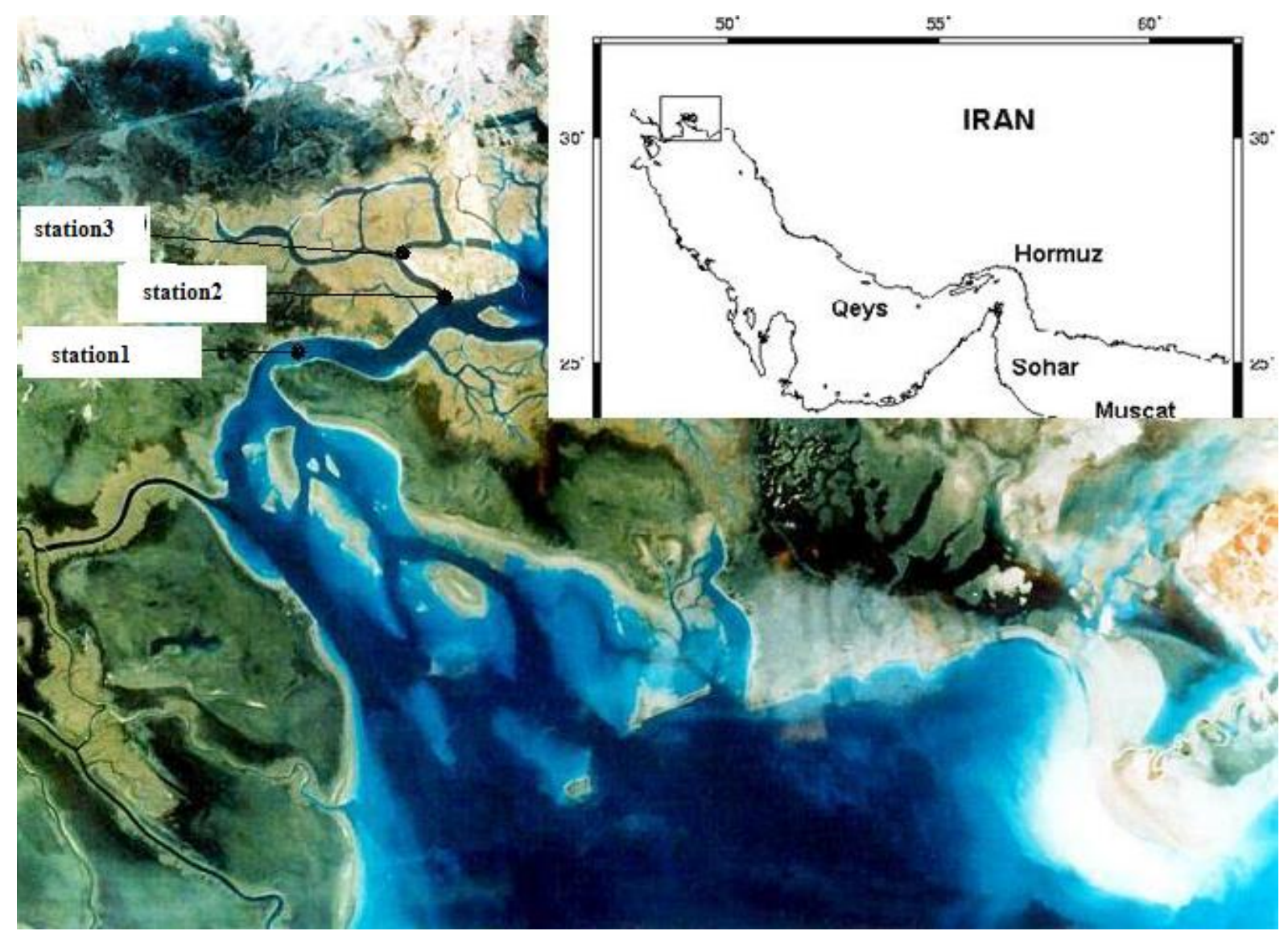

Fig. 1: Locations of the 3 samples in this study.station1:zangi estuary,station2:mahshahr estuary and station3:mousa estuary

\section{Retrieval of SST}

Image processing started with geometric and radiometric correction. Radiometric correction done by converting DN values in Landsat thermal band (band 11 and band 12) to radiance value, and then changed it to effective temperature value according to Landsat- 8 handbook.

The Split-Window (SW) algorithm was first proposed by McMillin who suggested using the differences in the atmospheric absorbance of two adjacent LWIR bands in order to accurately retrieve the sea surface temperature (SST) (McMillin,1975). The SWA is derived from a firstorder Taylor-series linearization of the radiative transfer equation and its formulation takes the general form of:

$\mathrm{T}_{\mathrm{s}}=\mathrm{A}_{0}+\mathrm{A}_{1} \mathrm{~T}_{10}-\mathrm{A}_{2} \mathrm{~T}_{11}$

where $T s$ is the SST, $\mathrm{T}_{10}$ and $\mathrm{T}_{11}$ are the brightness temperatures of TIRS bands 10 and 11, respectively, and $A_{0}, A_{1}$, and $A_{2}$ are coefficients.

The satellite data and in situ ground data should be concurrent within a period determined by the natural variation of the process being measured. We evenly divided the "matches" data into two parts: one part comprising 12 samples was used to construct the model for estimating SST from Landsat8 image data, and the other part comprising 12 samples was used for validation of the model.

Statistical analyses including calculations of linear regressions, were performed using SPSS 21.0 software (Statistical Program for Social Sciences). Correlation analysis was used to investigate the relationships between variables using SPSS software. Significance levels are reported to be significant $(p<0.05)$ or not significant $(p>0.05)$. The accuracy of algorithms was assessed by calculating root-mean-square error (RMSE) between measured and predicted values, using the following equations (Equation 3):

RMSE $=$

$\sqrt{1 / N \sum_{i=1}^{N}(\text { SSTmeasured }- \text { SSTestimated }) 2}$

Equation 3

where $\mathrm{N}$ is the number of samples, SST measured, is the measured SST, and SST estimated is the estimated SST.

\section{Retrieval of chlorophyll concentration}

Numerous bio-optical algorithms for chlorophyll

(C) retrieval have been developed to relate measurements of ocean radiance to the in situ 
concentrations of phytoplankton pigments.

O'Reilly et al. (1998) has carried out a comprehensive evaluation of a large number of semi-analytical and empirical bio-optical algorithms for data collected from different sources and different global locations during SeaWiFS BioOptical Algorithm Mini-workshop (SeaBAM). The data set used is ,known as the SeaBAM bio-optical data archive. Based on their analysis it was found that most of the empirical algorithms performed better than senti-analytical algorithms. Among the empirical algorithnas, cubic polynomial formulations such as Ocean Chlorophyll 2 (OC2) and Ocean Chlorophyll 4 (OC4) models were considered to be the best among all the empirical models. In the present study we have selected the six best empirical equations for evaluation using northwest Persian gulf biooptical data set. The selection of these algorithms was based on the results of the comparative analysis of O'Reilly et al. (1998). Table 1 shows the functional form of the algorithms used. The chlorophyll algorithms were evaluated using statistical and graphical criteria for $\mathrm{C}$ estimated by the models, and in-situ C. A regression analysis was performed between modeled and in-situ measured chlorophyll-a concentration values. Statistics such as coefficient of determination (r:) and root mean square error (RMSE) provide a numerical index of the model performance and graphical criteria such as scatter analysis provides indication on the non-linear behavior of the fit.

\section{Retrieval of Kd490}

The satellite data and in situ ground data should be concurrent within a period determined by the natural variation of the process being measured. We set the criterion for matching satellite and in situ observations, to maximize the number of possible matching pairs between satellite and in situ observations. Several algorithms have been developed for the remote sensing estimation of the diffuse attenuation coefficient at $=490 \mathrm{~nm}, \operatorname{Kd}(490)$. There are commonly two types of algorithms, first the empirical methods derived from in situ seawater optical and bio-optical data and the semianalytical model. In this study, we focused only on empirical algorithms.Table 1 shows the functional form of the algorithms used. The $\operatorname{kd}(490)$ were evaluated using statistical and graphical criteria for $\operatorname{kd}(490)$ estimated by the models, and in-situ $\mathrm{kd}(490)$. A regression analysis was performed between modeled and in-situ measured $\mathrm{kd}(490)$ values. Statistics such as coefficient of determination (r:) and root mean square error (RMSE) provide a numerical index of the model performance and graphical criteria such as scatter analysis provides indication on the non-linear behavior of the fit.

Zeu was calculated by chlorophyll concentration following the statistical algorithm proposed by Morel and Berthon (1989). In order to reduce the error caused by chlorophyll, we calculate it with following equation,

$\mathrm{Zeu}=2 \ln 10 / \mathrm{kd}=4.605 / \mathrm{kd}$ ( Equation 4)

\section{Results}

No one algorithms could meet the requirements of the evaluation criteria. Table 1 gives multivariate regression and algorithms results. Multiple regression models show better $\mathrm{R}^{2}$ than other algorithms. Among the regression models, we choose the best models for each ocean color parameter and estimate ocean color parameters from the image. The spatial and temporal distribution of the chlorophyll concentration in the parts of the Mousa creeks have been found to be same. Unlike the south Persian gulf, the chlorophyll concentration in the northwest of Persian gulf is low $(<1 \mathrm{mg} / \mathrm{m} 3)$ in general. The Chl-a concentrations ranged from 0.6 to $1.8 \mathrm{mg}$ $\mathrm{m}^{-3}$, with an average of $1.01 \pm 0.32 \mathrm{mg} \mathrm{m}^{-3}$. The maximal Chl-a values corresponded to strong phytoplankton blooms, which typically occurred in April; the lowest Chl-a value was observed in July. Fig. 2. Represent correlation between chlorophyll concentrations retrieved from landsat with in situ measurements (Fig.2). Figure 3 shows the Chl-a map of Mousa creeks from Feb 2014 to Nov 2014. 


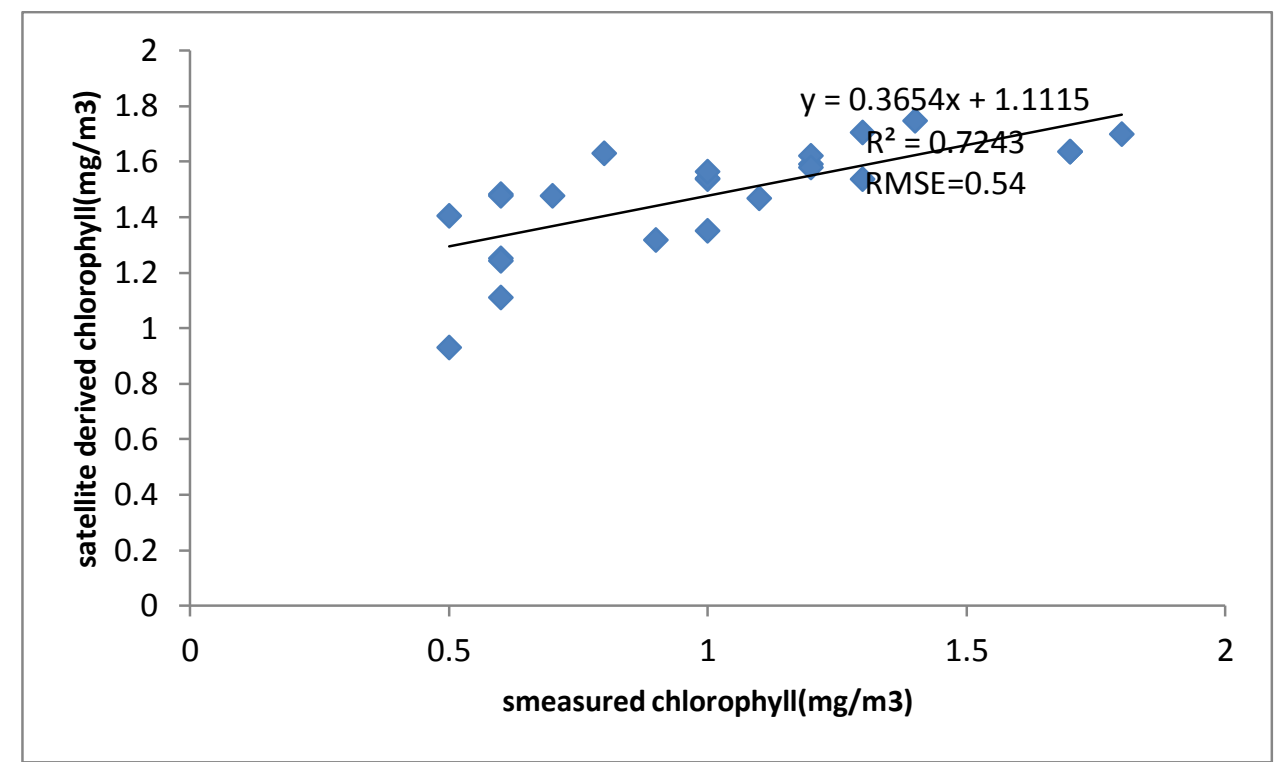

Fig.2:Correlation between chlorophyll retrieved from OLI with in situ measurements

Table 1. Functional form of the bio-optical algorithms and Summary of the statistical results of algorithms evaluation used in the study

\begin{tabular}{|c|c|c|c|}
\hline Algorithm & Empirical Equation & RMSE & $\mathrm{r}^{2}$ \\
\hline Aiken-C & $\begin{array}{l}\mathrm{C}=\exp (\mathrm{a} 0+\mathrm{a} 1 * \ln (\mathrm{R})) \\
\mathrm{R}=\mathrm{Lwn} * 490 / \mathrm{Lwn} 555 \\
\mathrm{a}=[0.745,-2.252]\end{array}$ & 1.2296 & 0.14 \\
\hline POLDER & $\begin{array}{l}\mathrm{C}=10^{\wedge}(\mathrm{a} 0+\mathrm{a} 1 * \mathrm{R}+\mathrm{a} 2 * \mathrm{R} 2+\mathrm{a} 3 * \mathrm{R} 3) \\
\mathrm{R}=\log (\mathrm{Rrs} * 443 / \mathrm{Rrs} 565) \\
\mathrm{a}=[0.438,-2.114,0.916,-0.851]\end{array}$ & 1.8668 & 0.13 \\
\hline Morel-3 & $\begin{array}{l}\mathrm{C}=10^{\wedge}(\mathrm{a} 0+\mathrm{a} 1 * \mathrm{R}+\mathrm{a} 2 * \mathrm{R}+\mathrm{a} 3 * \mathrm{R} 3) \\
\mathrm{a}=[0.20766,-1.828,0.75,-0.739]\end{array}$ & 0.9029 & 0.19 \\
\hline OC2 & $\begin{array}{l}\mathrm{C}=10^{\wedge}(\mathrm{a} 0+\mathrm{a} 1 * \mathrm{R}+\mathrm{a} 2 * \mathrm{R} 2+\mathrm{a} 3 * \mathrm{R} 3)+\mathrm{a} 4 \\
\mathrm{R}=\log (\operatorname{Rrs} 490 / \mathrm{Rrs} 555) \\
\mathrm{a}=[0.319,-2.336,0.879,-0.135,-0.071]\end{array}$ & 0.9452 & 0.11 \\
\hline OC4 & $\begin{array}{l}\mathrm{C}=10^{\wedge}(\mathrm{a} 0+\mathrm{a} 1 * \mathrm{R}+\mathrm{a} 2 * \mathrm{R} 2+\mathrm{a} 3 * \mathrm{R} 3)+\mathrm{a} 4 \\
\mathrm{R}=\log (\operatorname{Rrs} 443>\operatorname{Rrs} 490>\operatorname{Rrs} 510 / \operatorname{Rrs} 555) * \\
\mathrm{a}=[0.366,-3.067,1.93,0.649,-1.532]\end{array}$ & 1.4456 & 0.31 \\
\hline $\mathrm{OC} 3$ & $\begin{array}{r}\mathrm{C}=10^{\wedge}(\mathrm{a} 0+\mathrm{a} 1 \mathrm{R}+\mathrm{a} 2 \mathrm{R} 2+\mathrm{a} 3 \mathrm{R} 4) \\
\mathrm{R}=\log (\operatorname{Rrs} 443>\operatorname{Rrs} 488 / \mathrm{Rrs551}) \\
\mathrm{a}=[0.283,-2.753,1.457,0.659]\end{array}$ & 1.1499 & 0.13 \\
\hline $\begin{array}{r}\text { Multiple } \\
\text { regression 1 }\end{array}$ & Chla $=0.14+14.5 \times$ band $2-34 \times$ band $4+73.23 \times$ band 5 & 0.63 & 0.33 \\
\hline $\begin{array}{r}\text { Multiple } \\
\text { regression2 }\end{array}$ & Chla $=12.43+2.34($ band $2 /$ band 4$)+54.7 \times$ band 5 & 0.87 & 0.49 \\
\hline $\begin{array}{r}\text { Multiple } \\
\text { regression3 }\end{array}$ & $\begin{array}{r}\text { Chla }=11.3- \\
1.23 \times(\text { band} 2 / \text { band } 4)+17.8 \times \text { band } 2+123.5 \times \text { band } 5\end{array}$ & 0.54 & 0.52 \\
\hline Kd1 & $\mathrm{Kd} 490=0.0883[\mathrm{Lw}(443) / \mathrm{Lw}(550)]^{-1.491}+0.022$ & 0.4329 & 0.2232 \\
\hline $\mathrm{Kd} 2$ & $\mathrm{Kd} 490=0.1853[\operatorname{Rrs} 490 / \operatorname{Rrs} 555]^{-1.349}$ & 0.2542 & 0.6329 \\
\hline $\mathrm{Kd} 3$ & $\mathrm{Kd} 490=0.016+0.1565[\operatorname{Rrs} 490 / \operatorname{Rrs} 555]^{-1.540}$ & 0.3784 & 0.0002 \\
\hline $\mathrm{Kd} 4$ & $\begin{array}{l}\mathrm{Kd} 490=10\left(-0.8515-1.8263 \mathrm{R}+1.8714 \mathrm{R}^{2}-2.4414 \mathrm{R}^{3}-\right. \\
\left.1.0690 \mathrm{R}^{4}\right)+0.0166 \\
\mathrm{R}=\log 10(\mathrm{Rrs} 490 / \mathrm{Rrs} 555)\end{array}$ & 0.4113 & 0.1011 \\
\hline
\end{tabular}

*water-leaving radiance at different wavelengths *Rrs is remote sensing reflectance 


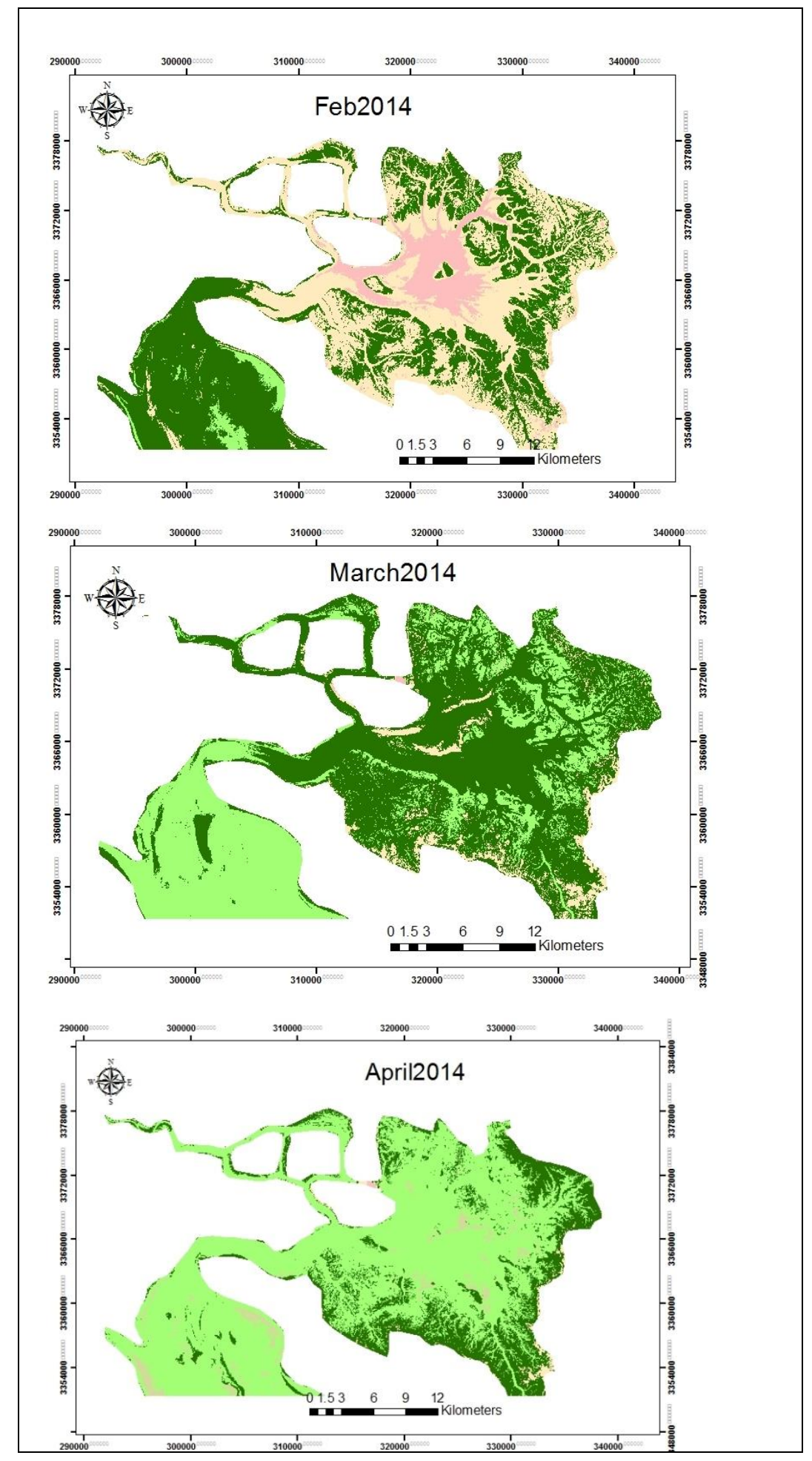




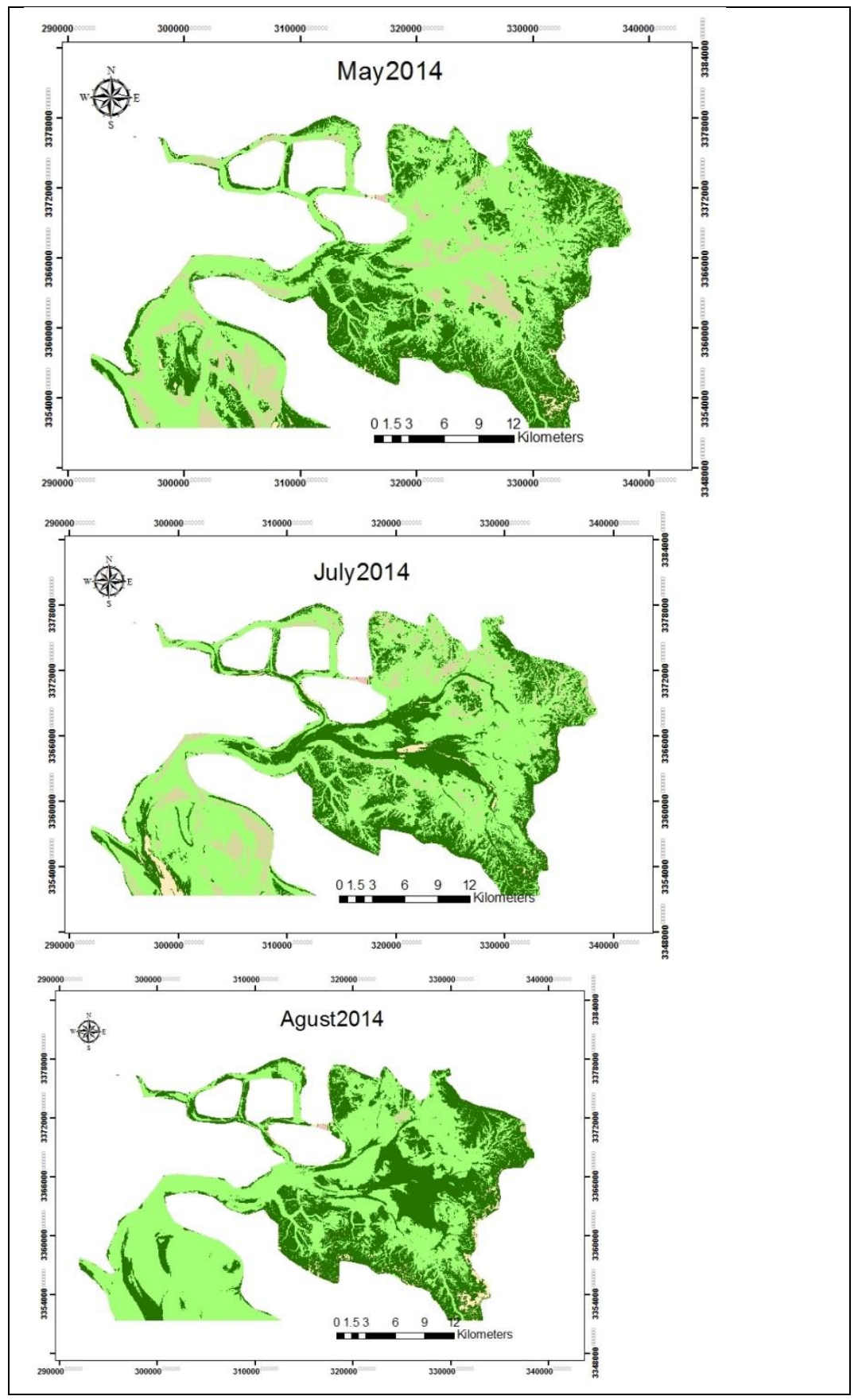




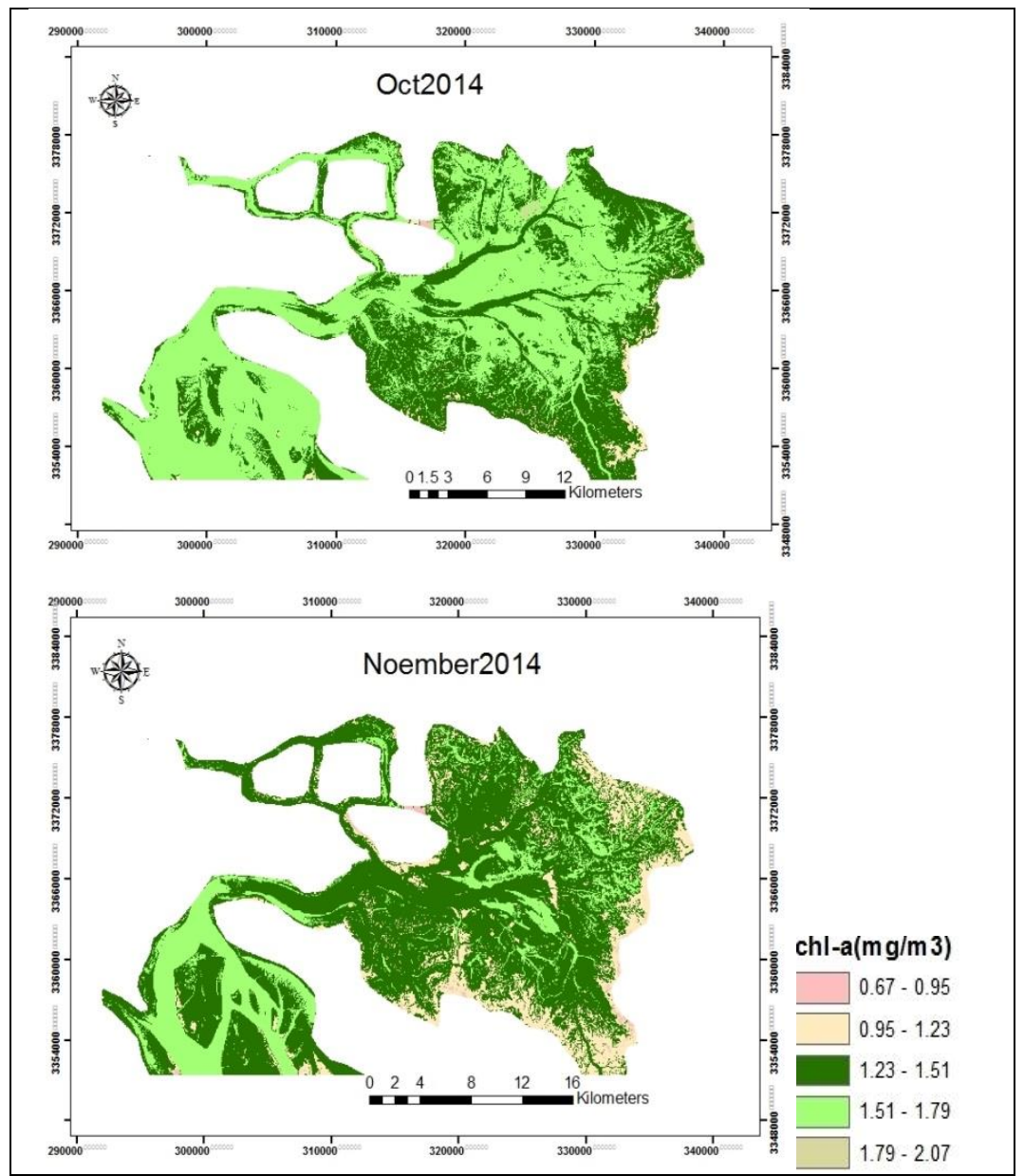

Fig 3. Landsat-derived chl-a distribution in Mousa creeks

There was not strong seasonal variability in $\operatorname{Kd}(490)$ over the entire creeks. The values for $\operatorname{Kd}(490)$ were highest $(0.86)$ in July and lowest $(0.59 \mathrm{~m})$ in February. Fig. 4 Represent correlation between kd(490) retrieved from landsat with in situ measurements(Fig. 4). Deeper Zeu are observed in Feb (7.8m) and Shallower Zeu are observed in July $(5.3 \mathrm{~m})$. Fig. 5 Represent correlation between Zeu retrieved from landsat with in situ measurements(Fig.5). Figure 6 shows the kd map of Mousa creeks from Feb 2014 to Nov 2014.

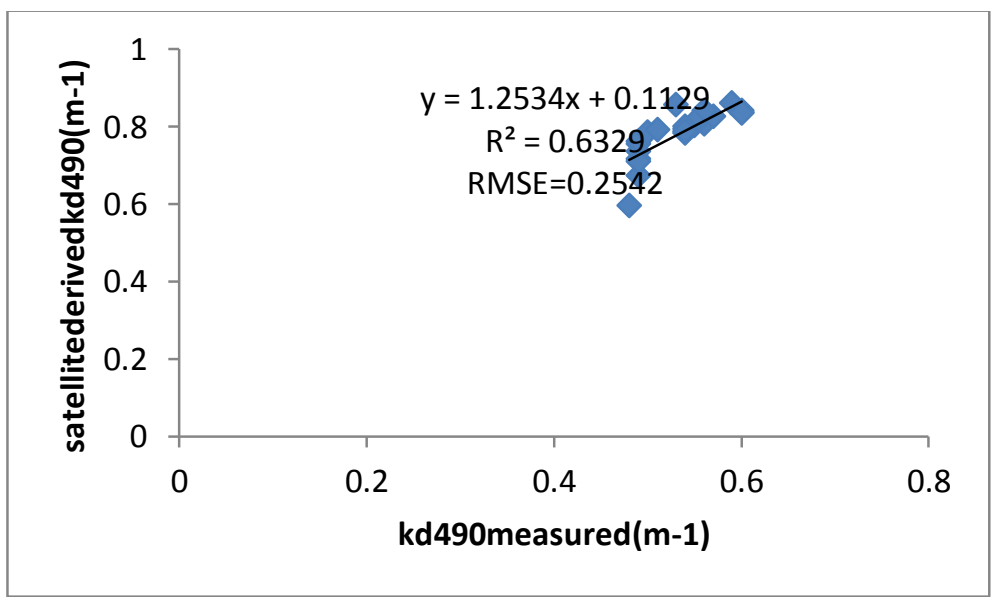

Fig.4:Correlation between kd490 retrieved from OLI with in situ measurements. 
Assessment of Chlorophyll-A, SST and Diffuse Attenuation Coefficient (Kd490) in Northwest of Persian Gulfu using Landsat 8 Satellite Data

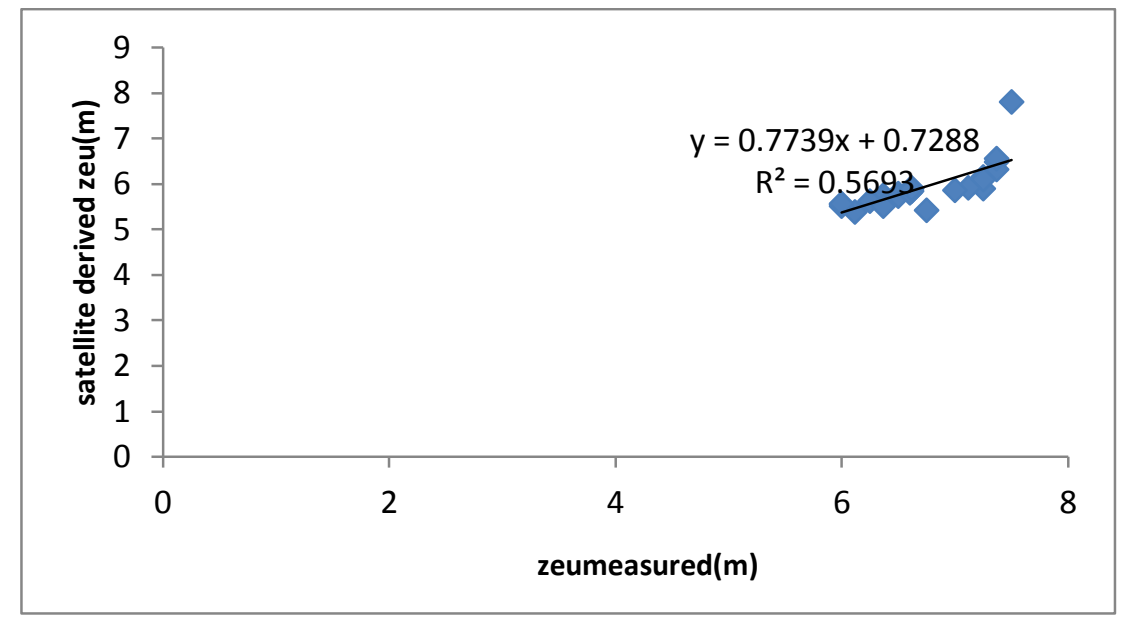

Fig.5:Correlation between Zeu retrieved from OLI with in situ measurements. 
Assessment of Chlorophyll-A, SST and Diffuse Attenuation Coefficient (Kd490) in Northwest of Persian Gulfu using Landsat 8 Satellite Data

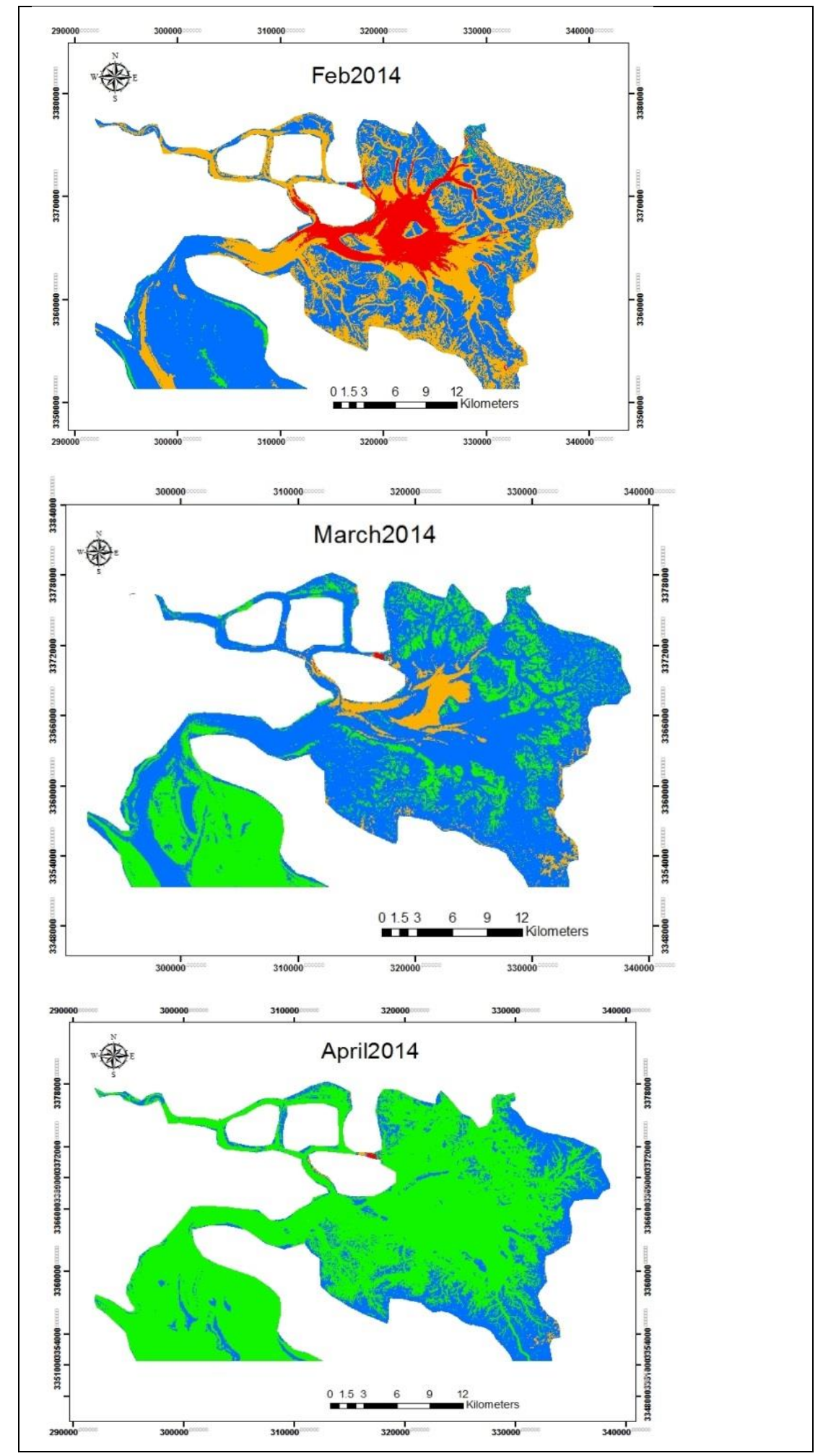




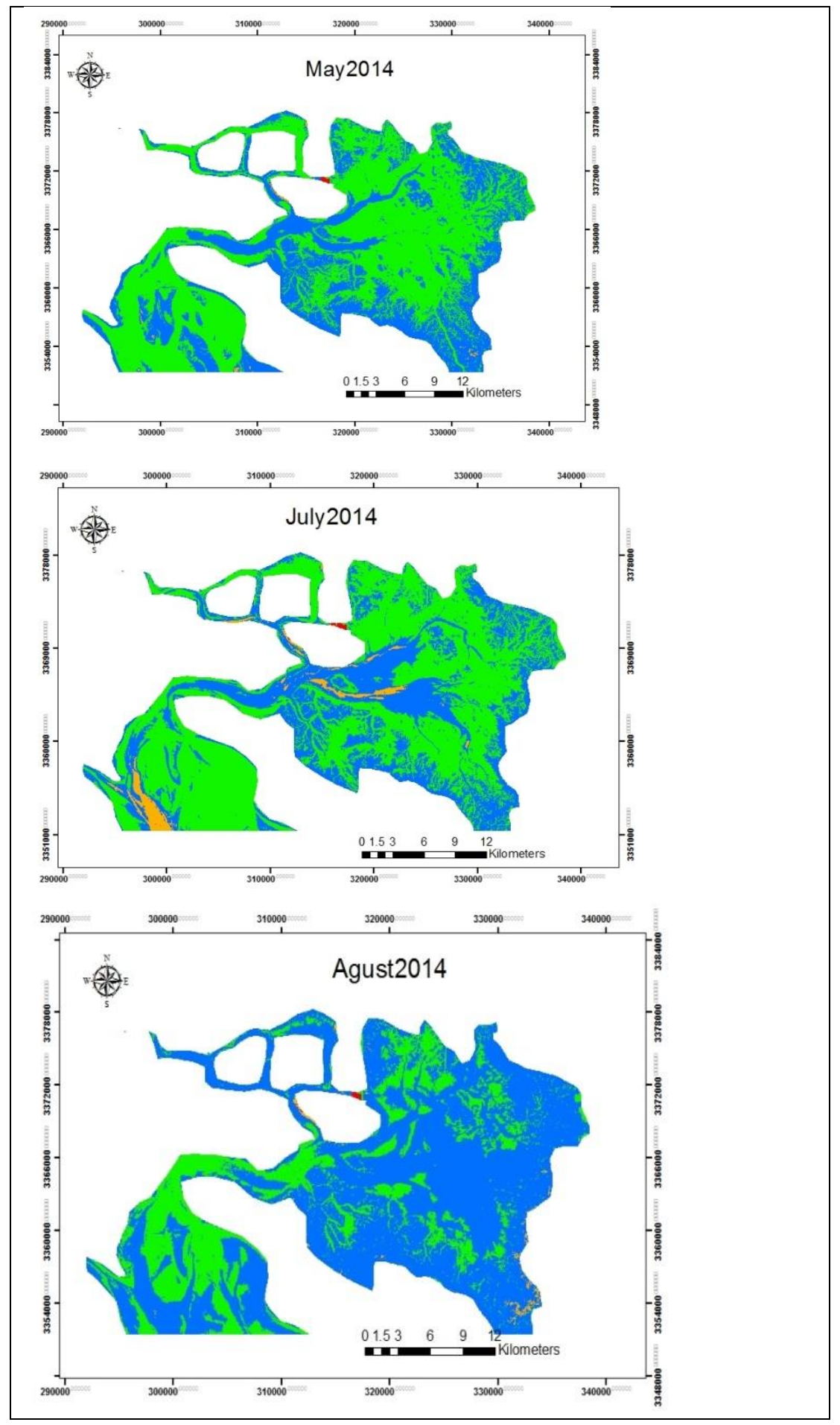




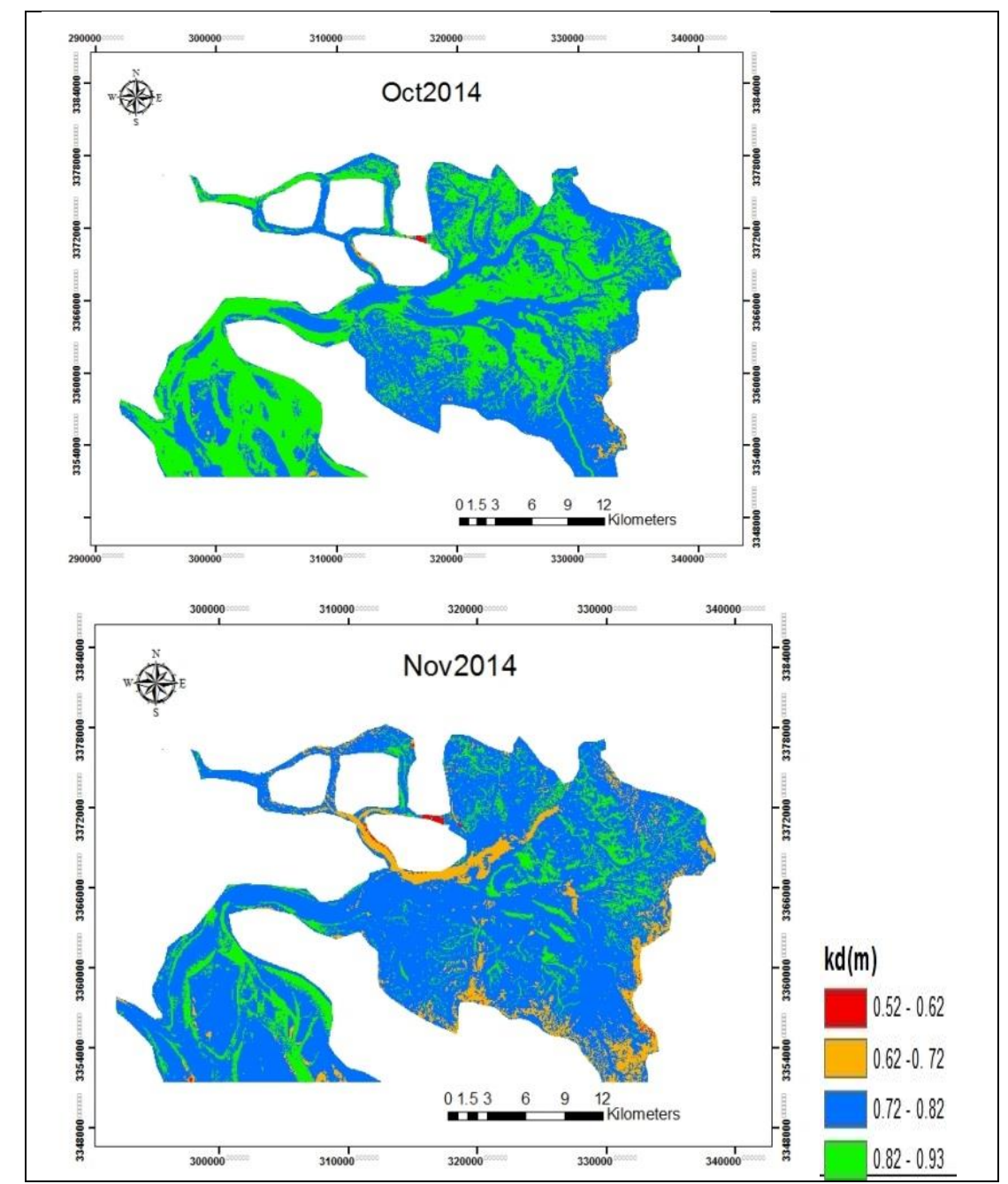

Fig 6. Landsat-derived kd distribution in Mousa creeks.

The results of analysis regression was shown in table2 (table.2). The development of SST algorithm model was conducted using the statistical correlation between $\mathrm{SST}_{\text {measured }}$ and $\mathrm{SST}_{\text {landsat. The }}$ algorithm is shown in equation 5 .

$\mathrm{SST}=0.356 * \mathrm{t}_{10}-1.053 *\left(\mathrm{t}_{10}-\mathrm{t}_{11}\right)+17.196$ (equation 5 )
The highest $\left(31 c^{\circ}\right)$ temperature was found in July and lowest temperature $\left(15.1 \mathrm{c}^{\circ}\right)$ was found in $\mathrm{Feb}$ (Fig.7). The determination coefficient between SST and chl-a was $\left(\mathrm{r}^{2}=0.009\right)$ (Fig.11). Fig. 8 Represent correlation between SST retrieved from landsat with in situ measurements. Figure 9 shows the SST map of Mousa creeks from Feb 2014 to Nov 2014.

Table 2. Regression coefficients, coefficient of determination, and Mean Square and standard error

\begin{tabular}{|ll|l|l|l|l|l|}
\hline Model & & Sum of Squares & df & Mean Square & F & Sig. \\
\hline \multirow{4}{*}{1} & Regression & 253.453 & 2 & 126.726 & 4.606 & $.022^{\mathrm{b}}$ \\
& Residual & 577.784 & 21 & 27.514 & & \\
& Total & 831.236 & 23 & & & \\
\hline
\end{tabular}




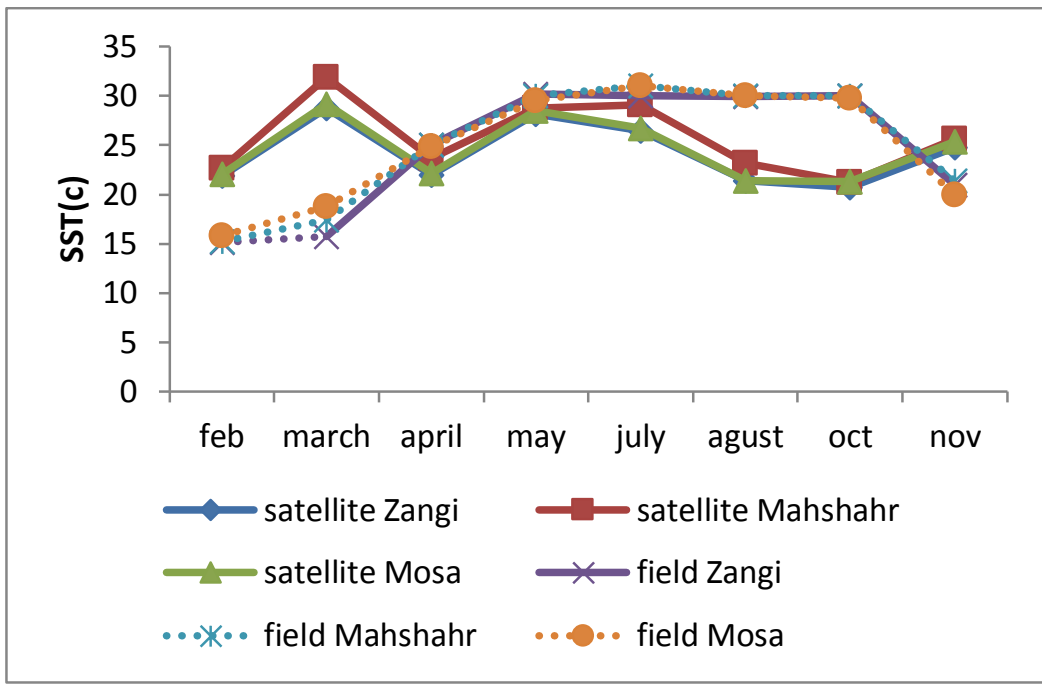

Fig. 7:Temporal variation of satellite derived and measured SST in this study

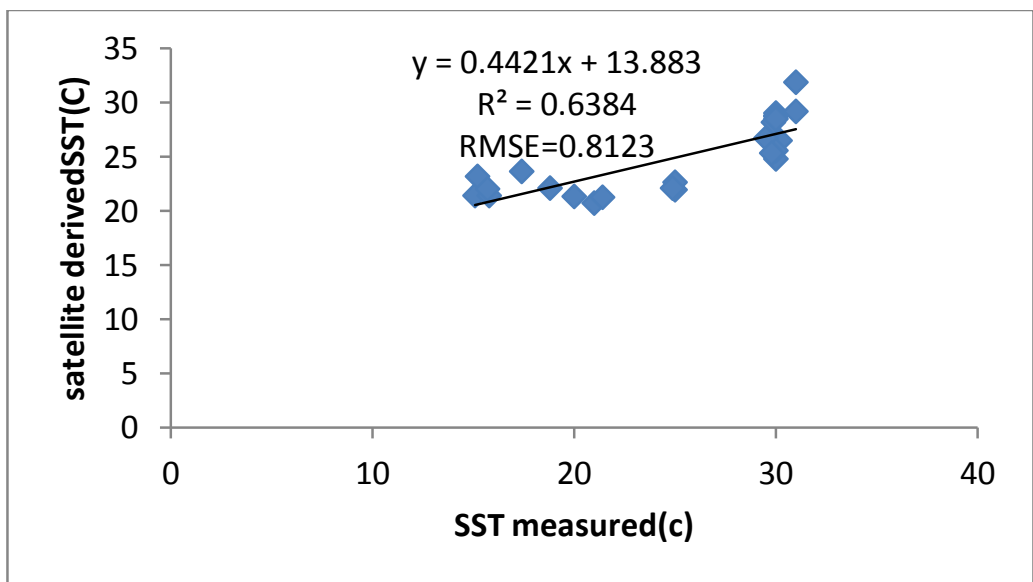

Fig.8: correlation between SST retrieved from landsat with in situ measurements 
Assessment of Chlorophyll-A, SST and Diffuse Attenuation Coefficient (Kd490) in Northwest of Persian Gulfu using Landsat 8 Satellite Data

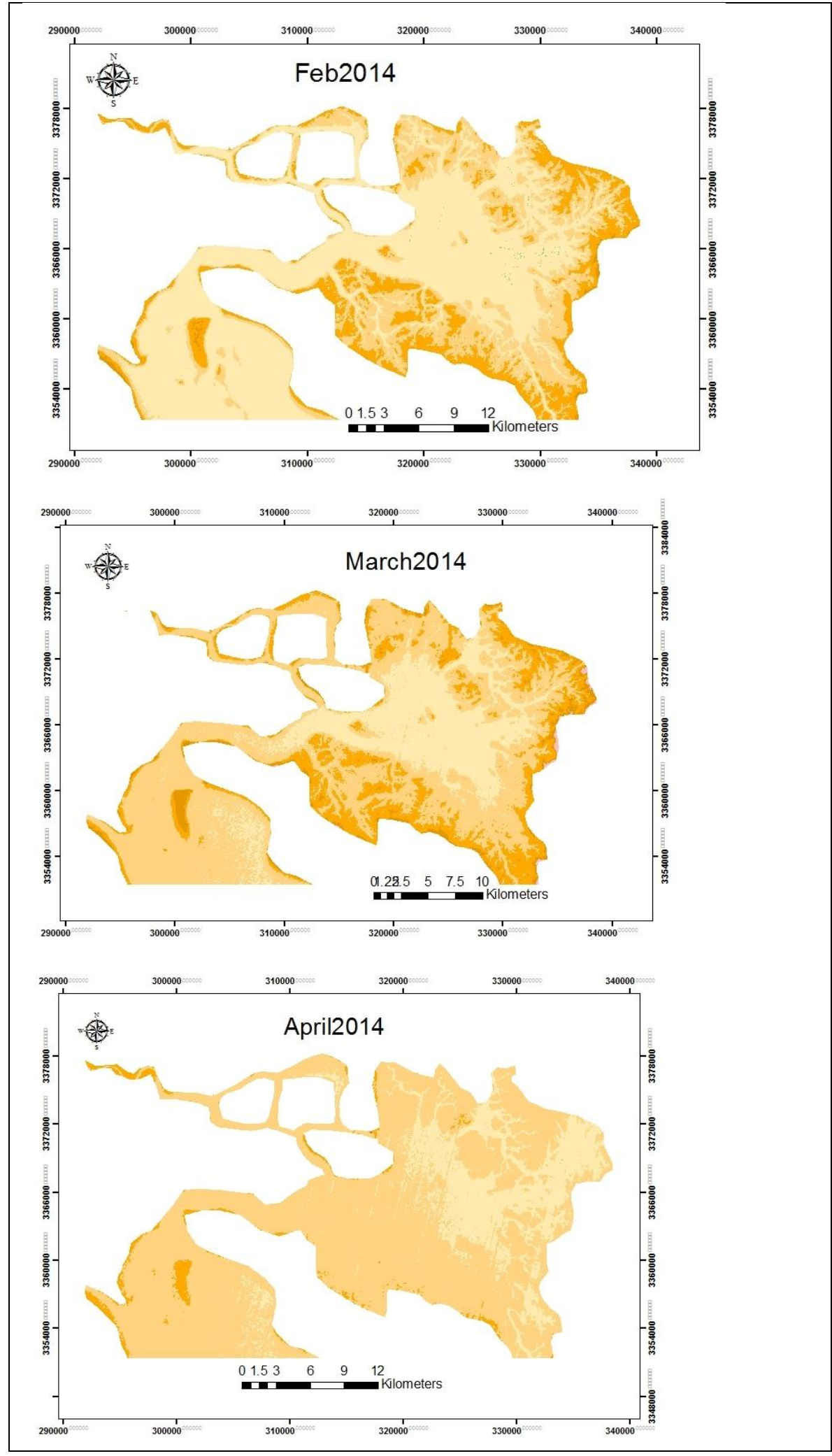




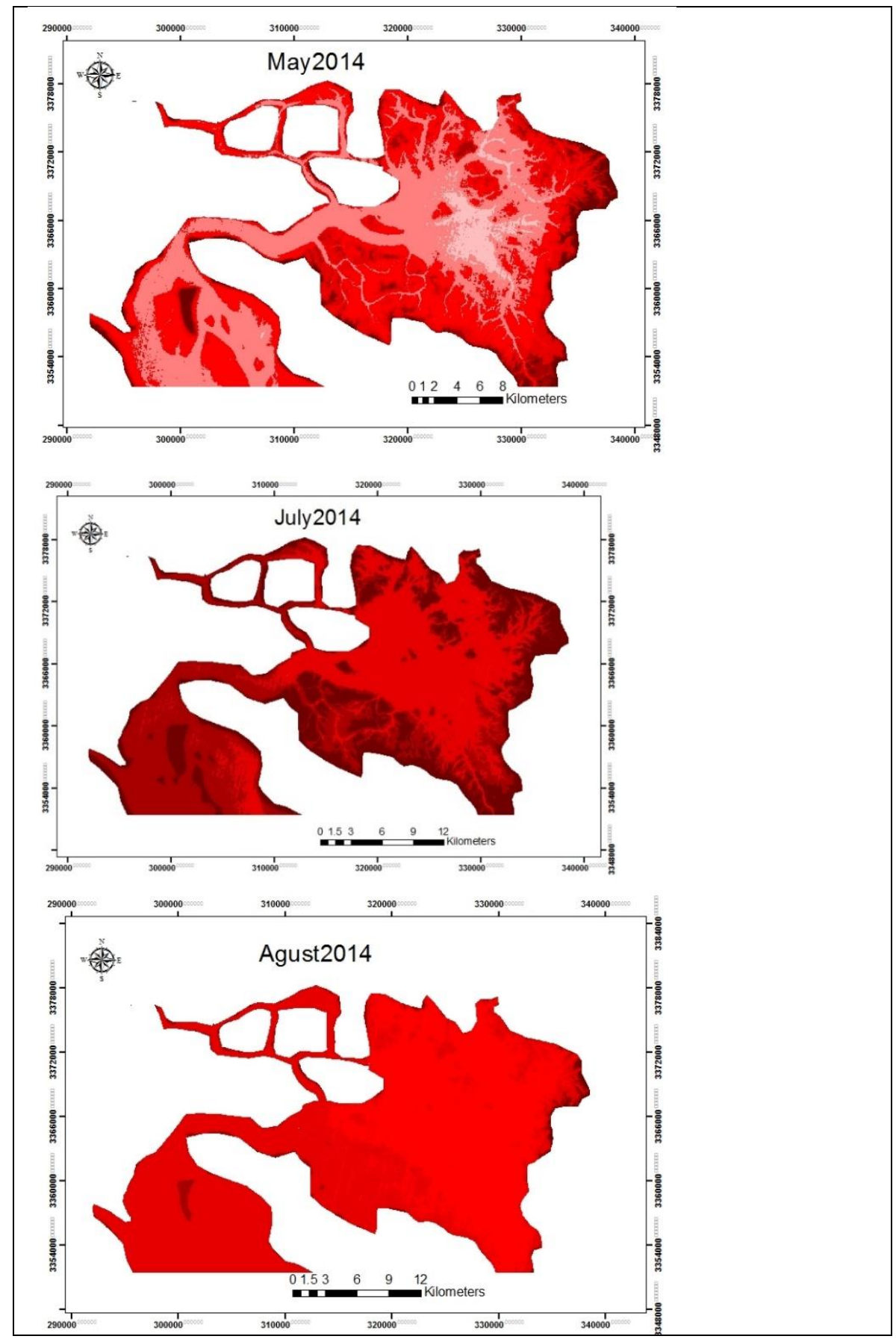




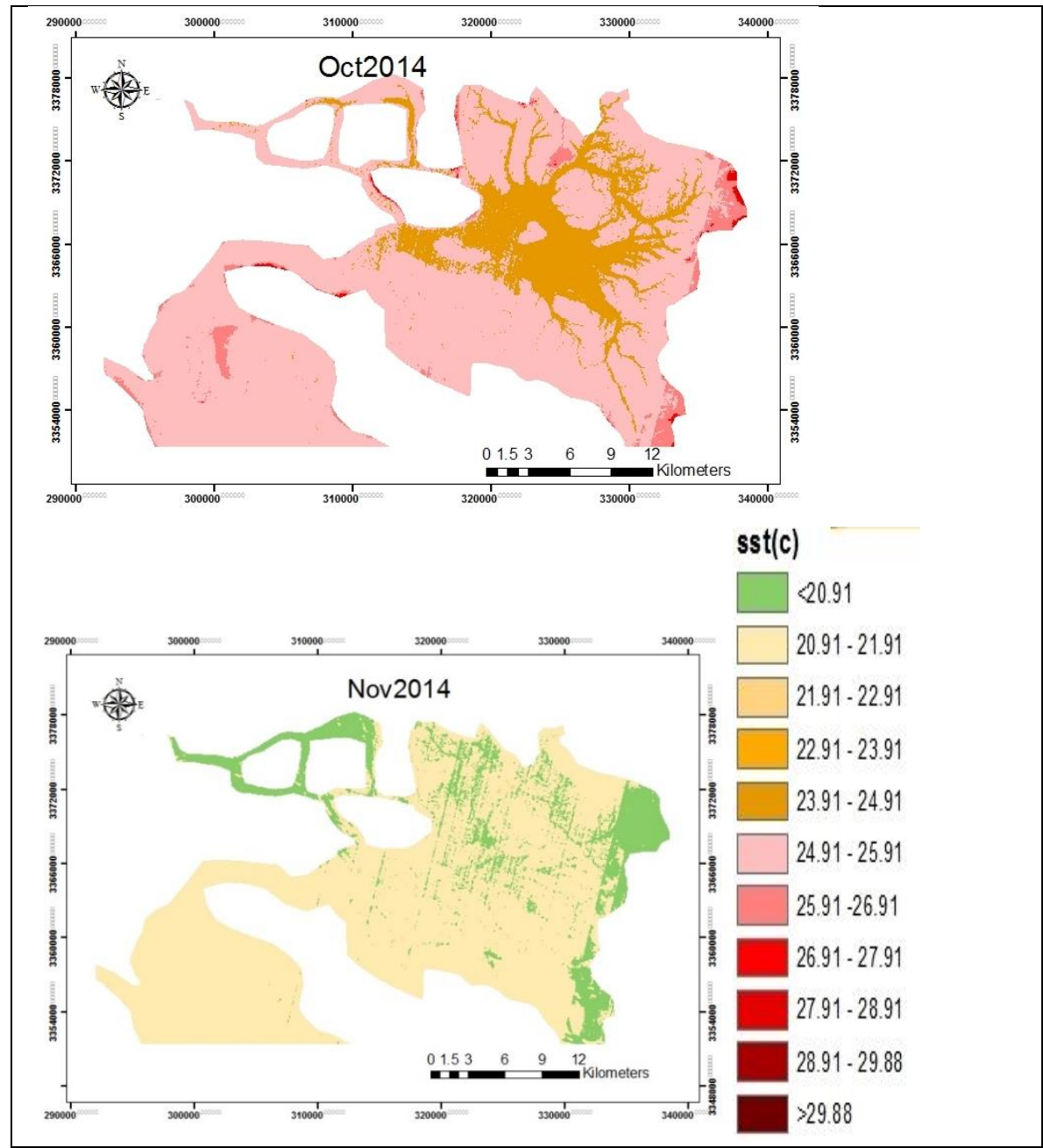

Fig 9. Landsat-derived SST distribution in Mousa creeks.

\section{Discussion and Conclusions}

Moabed (2006) have also found similar chlorophyll concentrations in the northwest using TM images. The chlorophyll concentrations in the southeastern have been found to decrease from the months of Feb-April. In the northeastern and the central Persian gulf, the chlorophyll concentrations show highest values in the month of Jan-Feb. In the Mousa creeks, though higher chlorophyll concentrations are found during the months of Avril-May, the seasonal variations are found to be very less. High value $\left(1.8 \mathrm{mg} / \mathrm{m}^{3}\right)$ in the chlorophyll concentration in the Mahshahr creeks in the month of April may be due to local effects. The results of this study indicate that no one bio-optical algorithms are capable of determining quantitative estimates of surface chlorophyll-a, using remotely sensed optical data in the Mousa creeks. Chlorophyll has two absorption peaks, on in the blue region $(440 \mathrm{~nm})$, and the other in the red (665 $\mathrm{nm})$ region of the electromagnetic spectrum. In an estuarine environment, other substances such as iron oxide, dissolved organic pigments and some algal pigments (e.g. carotenoids) also absorb blue and green light, which results in masking the response in this wavelength significant to chlorophyll a. Phytoplankton ,in which chlorophyll a is found, have other pigments with varying predominance which combine with the factors in producing the water's spectral reflectance (Cheshire et al., 1985 ;Stumpf and Tayler, 1988). The chlorophyll concentrations retrieved from multiple regression how good correlation $\left(\mathrm{R}^{2}=0.72\right)$ with the in situ measurements of chlorophyll concentrations.

The average range of sea surface temperature was recorded in between 15.1- 30.2degree Celsius. Spatial and temporal variation of SST in this zone show that distribution of SST varies with location. The location near to the shoreline suffered a higher surface temperature compared to the location farther. The distributions of higher surface temperature near the shore because, the contribution of suspended sediment that gives a higher reflectance of the surface area. The 
theoretical concepts explained that more sediment suspended at the ocean, the more the reflectance will be, thus the higher surface temperature was recorded.

Both the results was compared with theoretically idea of the typical SST since the absent of ground measurement data. However in various studies suggested that methodology used and algorithms proposed have been scientifically proven and could give a high accuracy in certain published literatures. The SST variation are a symbolic in further analysis towards the study of coastal management and fish industries development. Thus, SST can be calculated using SW algorithm on Landsat 8 with multiband OLI and TIR images.

About $\mathrm{kd}(490)$ we have validated this simple model, and demonstrated its utility in characterization of the spatial-temporal variations of $\mathrm{Kd}(490)$ distributions in Mousa creeks. Waters in Mousa creeks are consistently highly turbid year-round, and the highest and lowest $\operatorname{Kd}(490)$ were usually found in summer and winter, respectively. Spatially, the high $\operatorname{Kd}(490)$ values were observed in the northern part of the creeks, whereas the low $\operatorname{Kd}(490)$ values were recorded in central. Statistics from in situ validation and satellite data analysis suggest the estimates from the kd2 algorithm have sufficient fidelity to allow their use for temporal analysis of the Northwest Persian gulf coastal waters.

The estimated concentrations and the spatial and temporal variation of environmental indicators in this study in conjunction can be used to establish a better understanding of the physical and biological aspects of Mousa creeks dynamics. Due to the mixing of the two water types in the estuary, the environmental indicators often vary rapidly, both spatially and temporally. Any attempt to study these fluctuations will require an instantaneous and synoptic coverage at various tidal conditions. Landsat imagery is an ideal medium to provide information of this nature, subject only to cloud cover. The estimated present factors will contribute to our goal of calculating the primary production of Mousa creeks. In our future work, the Landsat products to calculate the primary production of Mousa creeks.

\section{References}

1) Arismendez, S., Kim, J., and Montagna, P., 2009. Application of watershed analyses and ecosystem modeling to investigate land-water nutrient coupling processes in the Guadalupe estuary, Texas, Ecological Informatics, 4(9): 243-253.

2) Baban,S.,1997. Environmental Monitoring of Estuaries; Estimating and Mapping Various Environmental
Indicators in Breydon Water Estuary, U.K., Using Landsat TM Imagery. Estuarine, Coastal and Shelf Science 44(2): 589-598.

3) Chauhan, P., Nagur, C. R. C., Mohan, M., Nayak, S. R., and Navalgund, R. R., 2001. Surface chlorophyll distribution in Arabian Sea and Bay of Bengal using IRSP4 ocean color monitor satellite data. Current Science, 80(6): 127- 129.

4) Chen, C., P. Shi, and Q. Mao., 2003. Application of remote sensing techniques for monitoring the thermal pollution of cooling-water discharge from nuclear power plant. Journal Environmental Science Healthy,8(8): 16591668.

5) Cheshire, H. M., Khorram, S. and Brockhans, J. A., 1985. Monitoring estuarine water quality from Landsat TM. International Conference on Advanced Technology for Monitoring and Processing Global Environmental Data, London U.K., pp 10-12.

6) Duarte, C. M., 1991. Seagrass depth limits. Aquatic Botany, 40(7):363-377.

7) KhalfehNilsaz, A., 1998. Investigation of primary production in Mahshahr creeks. MSc. thesis, Khoramshahr University of Science and Technology, $178 \mathrm{pp}$.

8) Kim,S., Kim,H .,Sin,J., Park, S., Park, K.2014. High resolution ocean color products estimation in fjord of Svalbard, Arctic sea. EARSeL 34th Symposium Proceedings, 16-20 June.

9) Lee, Z. P., Darecki, M., Carder, K., Davis, C., Stramski, D., and Rhea, W.,2005. Diffuse attenuation coefficient of downwelling irradiance: An evaluation of remote sensing methods. Journal of Geophysical Research, 11(5):12-23.

10) McMillin, L.M., 1975. Estimation of Sea Surface Temperatures from Two Infrared Window Measurements with Different Absorption. Journal of Geophysic Research, 80(12): 5113-5117.

11) Morel A, Berthon J F.,1989. "Surface pigments, algal biomass profiles and potential production of the euphotic layer: Relationships reinvestigated in view of remotesensing applications". Limnological Oceanogry,34, pp. 1545-1562.

12) Moabed, P., Rangzan,K., Savari, A., Khaledi,H., 2006. An overview of temporal and spatial patterns in satellitederived chlorophyll imagery.Journal of marine biology.4(2):34-45.

13) Ritchie, J.C. and Cooper, C.M., 2001. Remote sensing techniques for determining water quality: Application to TMDLs. In: TMDL Science Issues Conference, WaterEnvironment Federation, Alexandria, VA. 367-374p.

14) Suga, Y., Ogawa, H., Ohno, K., and Yamada, K., 2003. Detection of surface temperature from Landsat 7/ETM+. Advance. Space Research., 32(11):2235-2240.

15) Schott, J.R., 1982. An application of heat capacity mapping mission data: thermal bar studies of Lake Ontario. Journal Applied Photography Engeeniring, 8(3):117-120.

16) Schott, J.R., Barsi, J.A., Nordgren, B.L., Raqueło, N.G and de Alwis, D., 2001. Calibration of

17) Landsat thermal data and application to water resource studies. Remote Sensing of Environment,78 (12):108-117.

18) Stumpf, R.P. and Tayler, M.A., 1988. Satellite detection of bloom and pigment distributions in estuaries. Remote Sensing of Environment 24(9): 385404.

19) Thomas, A., Byrne, D. and Weatherbee, R., 2002. Coastal sea surface temperature variability from Landsat infrared data. Remote Sensing of Environment,81(3):262-272.

20) Wang,M. H., Shi,W., and Tang, J.W., 2011. Water property monitoring and assessment for China's inland Lake Taihu from MODIS-Aqua measurements. Remote Sensing of Environment, 115(11):841-854. 